Professor Anderson emphasizes in this paper the two crucial factors in implementing a management team concept: (1) the acceptance by the superintendent of the desirability of involving all sub-administrators in administrative planning and in policy formulation; and (2) the adoption of a formal structure which assures a system of open communication with all administrators.

\title{
Management Team Versus Collective Bargaining for Principals
}

LESTER W. ANDERSON

\begin{abstract}
A FEW years ago, it was common to hear principals attending the NASSP Convention make remarks critical of the adoption of collective bargaining by teachers. Comments such as these were heard:

"Collective bargaining is unprofessional."

"It will destroy a united profession."

"We are professionals, not laborers."

"Strikes are unethical and unprofessional."

"Collective bargaining will never happen in our school."

Yes, only a few years ago, principals were shocked at the thought of collective bargaining and strikes by teachers. What a change! I have been asked to address myself in this paper to the topic of the management team as a substitute for collective bargaining for principals. Be assured that making these statements forced me to do considerable soul searching about the questions

Lester W. Anderson is professor of education at the University of Michigan in Ann Arbor.
\end{abstract}


which might be most relevant to the present emotions of the Association. These are questions which I could not put aside:

1. Why are principals "up-tight" on this issue?

2. What have been the results of collective bargaining by teachers that have implications to the current discussion?

3. What are the major objectives principals hope to accomplish that are related to using either collective bargaining or a management team approach?

4. What are the long-term versus the short-term gains which might favor either approach?

Let me preface my remarks with the statement that I favor the management team concept over collective bargaining because I feel it has the possibility for producing greater benefits to principals on a long-term basis. I recognize that there may be situations in which collective bargaining produces results immediately that appear to be quite attractive, but I believe that the long-term disadvantages to the working relationships among administrators appear to outweigh the short-term gains.

\section{Appeal of Collective Bargaining}

It is not surprising that formal collective bargaining has appeal to many administrators. When principals view the substantial gains in salary and other welfare issues made by teachers, they cannot help but feel a little envious of the power and independence teachers have developed through collective bargaining. No longer do teachers accept passively that which a benevolent board and administrator have determined to be a fair salary for teachers. The militancy and the willingness of teachers to strike, even in situations in which strikes by teachers are considered to be illegal, has changed dramatically the popular image of teachers. Principals and the public have learned that teachers can be tough bargainers. They have approached the bargaining table with their homework well done, and they have held their own against the best negotiators boards of education have pitted against them. There can be little doubt but what teachers have generated confidence in their ability to look after themselves on salary and welfare issues. Certainly, they have gained greater power and financial progress on their own than they did working through administrators. 
It is not surprising that such results through collective bargaining have an appeal to an administrator who may not be completely happy with his own working conditions. This appeal is magnified in situations in which boards and superintendents have isolated the principal from the decision-making process, particularly in the bargaining process with teachers. Unfortunately, there have been cases in which the prerogatives and authority of the principal were bargained away with little consideration for his welfare, or with no involvement on his part in the decisionmaking process. There is little doubt but what principals who have been treated in this manner or who have not received salary adjustments commensurate with those of teachers are attracted to the power of formalized collective bargaining, for it does guarantee the right of administrators to protect and/or to bargain for their best interests. The point is granted that serious mistakes have been made by superintendents and boards of education in their relationships with principals. Salary inequities have developed which need correcting and greater involvement of principals in the decision-making process must be assured. Before making the decision to go the route of collective bargaining, however, principals are urged to examine the limitations of "boobytraps" that are inherent in it as compared to the advantages to be gained through a "team management" approach.

\section{Limitations of Collective Bargaining}

Most collective bargaining practices have adopted a labor model that forces those who use it into a labor rationale. The labor union rationale assumes a conflict of interest between management and labor, and it expects that their relationship will be in conflict. A logical outgrowth of this assumption is the expectation that labor and management are incompatible, with the resultant eternal conflict between them. This basic conflict has been institutionalized and formalized and manifested in collective bargaining procedures under labor laws.

Implicit, therefore, to using labor as a model for collective bargaining in education is the idea of irreconcilable conflict. What we have, if we follow collective bargaining under a labor model, is the establishment of a power relationship between the board of education, the superintendent of schools, and all administrators that involves treaty making and treaty enforcing. 
Both parties assume a power relationship with the fear of trouble if agreement is not reached, resulting in an endless struggle marked by an occasional armistice.

The ultimate consequence of such a procedure is to make it increasingly difficult for cooperative working relationships to prevail. Communication between adversaries is likely to become secretive and extremely superficial. Grievance procedures need to be established to make certain the treaty is properly enforced and that the rights of both sides are protected through threats of further trouble.

It is my position that working relationships of this type will destroy the higher motivating forces which grow out of a sense of satisfaction based on doing one's job well and gaining appropriate recognition by one's peers and other people within the organization for a job well done.

Although economic and welfare results gained through collective bargaining might reduce the immediate level of dissatisfaction among principals, particularly in those situations in which they have not been well treated financially or have not been included in policy formulation, they will not satisfy the motivation factors related to job satisfaction. Herein lies a fundamental weakness in the formalized collective bargaining approach; i.e., better salaries, improved welfare provisions, and resolution of short-term grievances can be achieved, but a high level of satisfaction with one's job performance is unlikely to be accomplished. As a matter of fact, cooperative working relationships can become so disrupted that the morale of the entire organization may deteriorate substantially.

Reliance on collective bargaining can be viewed as a lazy way to gain influence rather than by the quality of one's performance and the creative ideas which one contributes to the team. The traditional prerogatives and authority of the principal, also, can be diminished by reliance on specifications within the contract rather than the exercise of wisdom and leadership by the person. Administrative decisions based on frequent checking of the specifications in the contract hardly excites the person who prides himself on being a professional administrator.

\section{Major Difference}

A major difference between the labor-management adversary relationship in industry and the professional relationship in 
schools is related to the fact that industrial managers usually have not been laborers. The typical industrial plant manager or executive graduates from college and immediately enters into a training program for management within a company or is assigned to managerial duties very early in his career. In contrast, virtually all school administrators have been teachers and have been promoted from the ranks of teachers to administration. It appears as though administrators should be sensitive, therefore, to the needs of their subordinates and should rely on understanding, trust, and cooperation in their working relationships.

It is proposed, therefore, that a "team management" approach, properly applied, can resolve the welfare problems of the principals as well as create cooperative and effective working relationships among administrators which will produce greater job satisfaction to all concerned when viewed on a long-term basis.

\section{Team Management Approach}

The team management concept has received considerable attention during this past year. A number of state and national periodicals have carried articles describing it. Both state and regional meetings of administrators and board of education members have featured it as a topic for discussion. It is assumed, for the purposes of this paper, that most administrators have read these materials and/or have been involved in discussions concerning team management. The major concern at this time is to assess its potential for correcting deficiencies in the administrative process which have occurred as a result of recent disruptions in the traditional relationships of administrators and its potential for providing administrative structures and procedures that will enhance the welfare and job satisfaction of principals on a longterm basis.

It is conceded that the success of a management team concept is only partially within the control of principals. The superintendent continues to occupy the pivotal position in the working relationship. It is the superintendent who has the final responsibility for administering the policies of the board. Typically, the board delegates authority to the superintendent to determine an administrative structure in harmony with his philosophy and his expectations of subordinate administrators.

Although the superintendent has a relatively free hand in determining how the school shall be administered, he is de- 
pendent upon other administrators within the system to implement whatever plan he chooses to follow. Sharing of authority with principals and other administrators is essential for effective administration of the system. Under a team management system, all "line" administrators, including principals, can be thought of as being extensions of the superintendent with appropriate authority designated in keeping with their assigned duties.

From the viewpoint of the superintendent, his effectiveness would be handicapped seriously if he could not depend upon the loyalty and cooperation of all sub-administrators in the execution of school policies. As an extension of the office of the superintendent, all administrators are an integral part of the final authority of the executive branch of the school system. Within the authority structure, all administrators must be part of the management team and must be held accountable to the superintendent for their actions. Any disruption in the cooperative relationships between the superintendent and his sub-administrators places a serious handicap on the effective administration of the schools.

The question is not whether there should be a management team; rather, the issue is how it should be organized to maximize its effectiveness and how it will relate to the superintendent's style of administration. If the superintendent is committed to a philosophy of participatory management, an internal structure will be adopted which is characterized by open communication and mutual dependence among administrators in developing policy recommendations for the board and in planning administrative procedures for the system as a whole. Cooperative working relationships would be expected under such a philosophy, and the management team concept would be the natural consequence in this situation.

\section{Jeopardizing the Management Team}

When the superintendent implements a structure and a philosophy of open communication, involving all administrators in the determination of policies, the management team concept is operating at its best with mutual trust and confidence characteristic of the administrative climate. It is not difficult to identify situations, however, in which the superintendent of schools is reluctant to delegate authority to sub-administrators and assumes the position 
that he alone is capable of determining administrative policieswithout the advice and counsel of anyone. Directives are issued and compliance is demanded. Channels of communication among administrators become a one-way proposition resulting in feelings of antagonism and frustration by those on the receiving end of the communication. It is in situations of this type that sub-administrators seek structural alternatives to assure representation of their viewpoints. When this occurs, formation of a collective bargaining unit becomes very attractive to principals and other administrators below the superintendent. Certainly, the management team concept is in jeopardy in this situation. But the reason it is in jeopardy, is that the superintendent has either rejected the use of an internal structure that provides for cooperative planning among administrators or he has been ineffective in implementing such a structure.

It is emphasized that the crucial factors in implementing a management team concept are: (1) the acceptance by the superintendent of the desirability of involving all sub-administrators in administrative planning and in policy formulation: and (2) the adoption of a formal structure which assures a system of open communication with all administrators.

When these conditions prevail, the stage is set for a constant interchange of ideas on school affairs, including salaries and welfare benefits for administrators. It is this condition which maximizes the operation of factors related to the job satisfaction of principals. Not only is it possible to reduce the level of dissatisfaction through such a relationship, it is possible also to include within a team management plan procedures by which administrators can negotiate on a collective basis on welfare issues. A common misunderstanding is that implementation of a management team concept excludes administrators from using the negotiating process. Negotiating procedures are compatible with a management team concept providing they remain independent from alliances with labor oraganizations and do not assume an adversary relationship with the superintendent and the board. Principals are a part of management and should not become bogged down in an anti-management rationale. It is suggested that we might have the best of two worlds under a team management plan, i.e., cooperative working relationships among all administrators and the board, as well as provisions for collective negotiations on welfare matters. 


\section{Conclusions}

Disruptions in the traditional roles of administrators have occurred as a result of collective bargaining. It has forced boards of education and administrators to redefine or clarify their roles and working relationships. One idea growing out of this ferment in administration is a commitment to the management team concept.

The extent to which this concept will be implemented is related to: (1) the extent to which all parties involved really want a working relationship based on a philosophy of involvement in policy formulation of all individuals affected by the policy, and (2) the skill with which the superintendent and his staff design a structure which assures a process of open communications among all administrators in the decision-making process. When these conditions are optimal, the concept can be instituted without the need for a separate collective bargaining body.

Although major responsibility for implementing a management team belongs to the superintendent, the principals must also accept the philosophy and viewpoint basic to it. Support of the superintendent and the board of education at this particular point is crucial. It appears as though both of these groups are exerting considerable effort to correct mistakes of the past few years which have not always been compatible with a management team philosophy. Progress is being made. Let us make certain in local situations that the management team concept has been given a fair trial before adopting a system of collective bargaining based on labor laws and procedures which place the possibility of a management team in serious jeopardy.

The future patterns of educational administration are at stake. Decisions made now may establish organizational structures of long duration. It is a challenge to all administrators to analyze the problems confronting them and the alternative solutions available. It is hoped that local decisions will follow a pattern that is supportive of a management team, based on cooperative working relationships throughout the entire organization. It is easy to accept a power relationship which appears to offer relief to immediate problems, but it is extremely difficult to control power relationships once they have been adopted. A little patience and effort on our part now may pay substantial dividends on a longterm basis. 